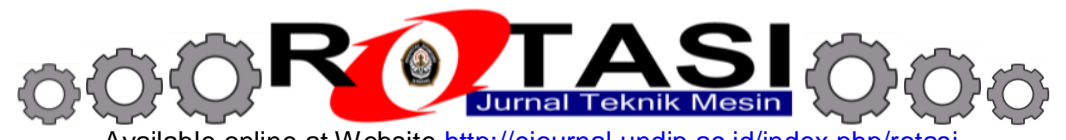

Available online at Website http://ejournal.undip.ac.id/index.php/rotasi

\title{
PENENTUAN ENERGI AKTIVASI PEMBAKARAN BRIKET CHAR SAMPAH KOTA DENGAN MENGGUNAKAN METODA THERMOGRAVIMETRY DAN ISOTHERMAL FURNACE
}

\author{
Dwi Aries Himawanto \\ Jurusan Teknik Mesin, Fakultas Teknik, Universitas Sebelas Maret \\ Jl. Ir. Sutami no. 36A Surakarta, Telp/Fax: +62271632163 \\ E-mail: dwi_ah@uns.ac.id,dwiarieshimawanto@gmail.com
}

\begin{abstract}
ABSTRAK
Penelitian ini bertujuan mencari energi aktivasi pembakaran briket char sampah kota dengan metoda thermogravimetry dan isothermal furnace. Penelitian diawali dengan pembuatan briket char dengan komposisi $75 \%$ sampah organik dan $25 \%$ yang dilakukan dengan jalan ditekan dalam sebuah mesin pres hingga berbentuk silindris, dengan tekanan pengepresan 250 $\mathrm{kg} / \mathrm{cm}^{2}$ dan lama holding time (penahanan tekanan) selama 1 menit. Briket arang sampah kota tersebut dibuat dengan menggunakan perekat tepung kanji dengan berat $20 \%$ dari berat total briket. Berat sampel briket char sampah kota adalah seberat 3 gram. Selanjutnya dilakukan uji laju pembakaran dengan menggunakan dua metode, metode pertama adalah metode thermogravimetry yang dilakukan dengan cara menaikkan temperatur ruang bakar dari temperatur kamar secara bertahap dengan besar kenaikan konstan tiap waktu sebesar 20 ${ }^{0} \mathrm{C} /$ menit, sampai sampel bahan bakar terbakar habis, sementara metode yang kedua adalah metode isothermal furnace, dimana briket char sampah akan diletakkan dalam reaktor dengan temperatur ruang tertentu sampai terbakar habis, variasi temperatur ruang bakar yang dipilih adalah $250{ }^{\circ} \mathrm{C}, 500{ }^{\circ} \mathrm{C}$ dan $600{ }^{\circ} \mathrm{C}$. Pada pengujian pembakaran secara isothermal furnace dilakukan pada kecepatan aliran udara $0,1 \mathrm{~m} / \mathrm{s}$. Hasil penelitian menunjukkan bahwa metoda isothermal furnace dapat digunakan untuk melakukan perhitungan energi aktivasi pembakaran seperti halnya metoda thermogravimetry, dengan memperhatikan pemilihan suhu reaktor yang dipilih, banyaknya kondisi isothermal yang digunakan serta sifat-sifat fisis dari briket.
\end{abstract}

Kata Kunci: energi aktivasi, pembakaran, briket char, thermogravimetry, isothermal

\section{PENDAHULUAN}

Salah satu upaya untuk mengatasi masalah semakin menipisnya cadangan sumber energi fosil adalah dengan menemukan sumber energi alternatif yang memiliki cadangan yang berlimpah dan salah satu alternatif sumber energi tersebut adalah sampah kota. Dalam hal pengolahan sampah kota menjadi sumber energi, salah satu teknologi konversi energi yang biasa dilakukan adalah melalui cara pirolisis menjadi char untuk kemudian mengalami proses pembakaran.

Definisi proses pembakaran adalah suatu reaksi kimia eksotermal dengan kalor yang dibangkitkan sangat besar dan menghasilkan nyala, dimana reaksi ini berlangsung spontan dan berkelanjutan karena adanya suplai kalor yang dibangkitkan oleh reaksi itu sendiri. Secara lengkap, proses pembakaran bahan bakar padat secara proses fisis meliputi tiga tahapan, yaitu tahap pengeringan, tahap devolatilisasi, tahap pembakaran arang, dan akan tersisa abu [1]. Dalam proses pembakaran, jenis bahan baku merupakan salah satu parameter yang penting dalam proses pembakaran, selain itu periode pembakaran arang merupakan periode yang penting dalam proses pembakaran pellet berbahan dasar biomassa [2]. Pengolahan sampah rumah tangga melalui proses pirolisis dengan laju kenaikan suhu $10{ }^{0} \mathrm{C} / \mathrm{menit}$ hingga suhu ruang mencapai $666{ }^{\circ} \mathrm{C}$ yang dilanjutkan dengan proses pembakaran dengan memanaskan ruang pembakaran dengan laju kenaikan suhu $10{ }^{\circ} \mathrm{C} /$ menit hingga suhu ruang bakar mencapai $1270{ }^{\circ} \mathrm{C}$, menunjukkan bahwa selama proses pirolisis terjadi pengurangan berat sampel sebesar $60 \%$ dan dengan penelitian tersebut diperkirakan energi yang mampu diselamatkan sebesar $20.000 \mathrm{~kJ} / \mathrm{kg}$ [3]. Proses pirolisis dan pembakaran dari sampah juga dilakukan pada 5 sampel berbahan baku kayu, 6 sampel berbahan baku plastik dan 2 sampel RDF (Refuse Derived Fuel). Pirolisis dilakukan pada kisaran suhu $30{ }^{\circ} \mathrm{C}$ sampai dengan $1000{ }^{\circ} \mathrm{C}$ dengan laju kenaikan suhu $20{ }^{0} \mathrm{C} / \mathrm{menit}$. Untuk proses pembakaran dilakukan dengan kondisi termal yang sama. Hasil penelitian menunjukkan bahwa kinetika reaksi dekomposisi $R D F$ merupakan penjumlahan dari kinetika komponen penyusunnya dan juga $R D F$ dengan komponen plastik yang lebih tinggi menghasilkan char yang lebih rendah dengan reaktivitas yang rendah [4]. Prediksi kinetika reaksi bahan bakar dinyatakan dalam sebuah parameter disebut reaktivitas (reactivity) [5].

Dalam penelitian mengenai pembakaran, salah satu parameter yang penting untuk diteliti adalah energi aktivasi pembakaran, yaitu energi minimum yang diperlukan agar suatu reaksi pembakaran dapat berjalan. Energi aktivasi pembakaran lazim ditentukan dengan menggunakan metoda thermogravimetry, namun demikian salah satu kendala metoda thermogravimetry adalah diperlukan sistem kontrol suhu ruangan yang mampu menghasilkan heating 
rate yang konstan per satuan waktu, hal inilah yang menjadikan metoda thermogravimetry cukup sulit untuk dilakukan, karena memerlukan alat kontrol suhu yang cukup sensitif. Disisi lain, terdapat metoda isotermal furnace yang lebih mudah dalam pengoperasiannya, namun jarang digunakan untuk menguji energi aktivasi. Dalam artikel ini disajikan perbandingan metoda thermogravimetry dan metoda isothermal furnace untuk mengkalkulasi energi aktivasi pembakaran briket char sampah kota.

\section{METODE PENELITIAN}

\subsection{Material Penelitian}

Material yang digunakan dalam penelitian ini adalah char (arang) yang dihasilkan dari proses pirolisis sampah kota terseleksi dengan komposisi $75 \%$ sampah organik dan $25 \%$ sampah anorganik, terminologi sampah organik mengacu pada campuran sampah daun pisang dan sampah bambu, sementara terminologi sampah anorganik mengacu pada sampah kemasan dan sampah styrofoam. Proses pirolisis untuk mendapatkan char tersebut dilakukan dengan kondisi operasi temperatur akhir pirolisis $400{ }^{\circ} \mathrm{C}$, heating rate $10{ }^{\circ} \mathrm{C} /$ menit serta holding time (waktu penahanan suhu akhir) 30 menit yang dilakukan dalam sebuah fixed bed reactor dan untuk menjamin bahwa dalam proses pirolisis tidak ada oksigen yang bereaksi maka selama proses pirolisis dihembuskan gas nitrogen dengan kapasitas $100 \mathrm{ml} / \mathrm{menit}$ dari bawah reaktor.

\subsection{Peralatan yang Digunakan}

Skema peralatan uji pembakaran yang digunakan dalam penelitian ini dapat dilihat dalam Gambar 1. Dalam gambar tersebut, terlihat bahwa alat utama uji pembakaran berupa silinder yang dililiti dengan elemen pemanas, elemen pemanas tersebut dihubingkan dengan thermocontroller guna mengatur pasokan panas hingga didapatkan heating rate (laju pemanasan) atau temperatur akhir sampel yang diinginkan. Pengamblian data berupa perubahan massa sampel dilakukan dengan menggunakan timbangan analitik dengan merk A\&D dengan tipe GF-300. Peralatan juga dilengkapi dengan modul data logger yang berfungsi sebagai akuisisi data suhu sampel. Data logger yang digunakan adalah merk ADAM 4018 yang memiliki 8 channel sambungan thermocouple

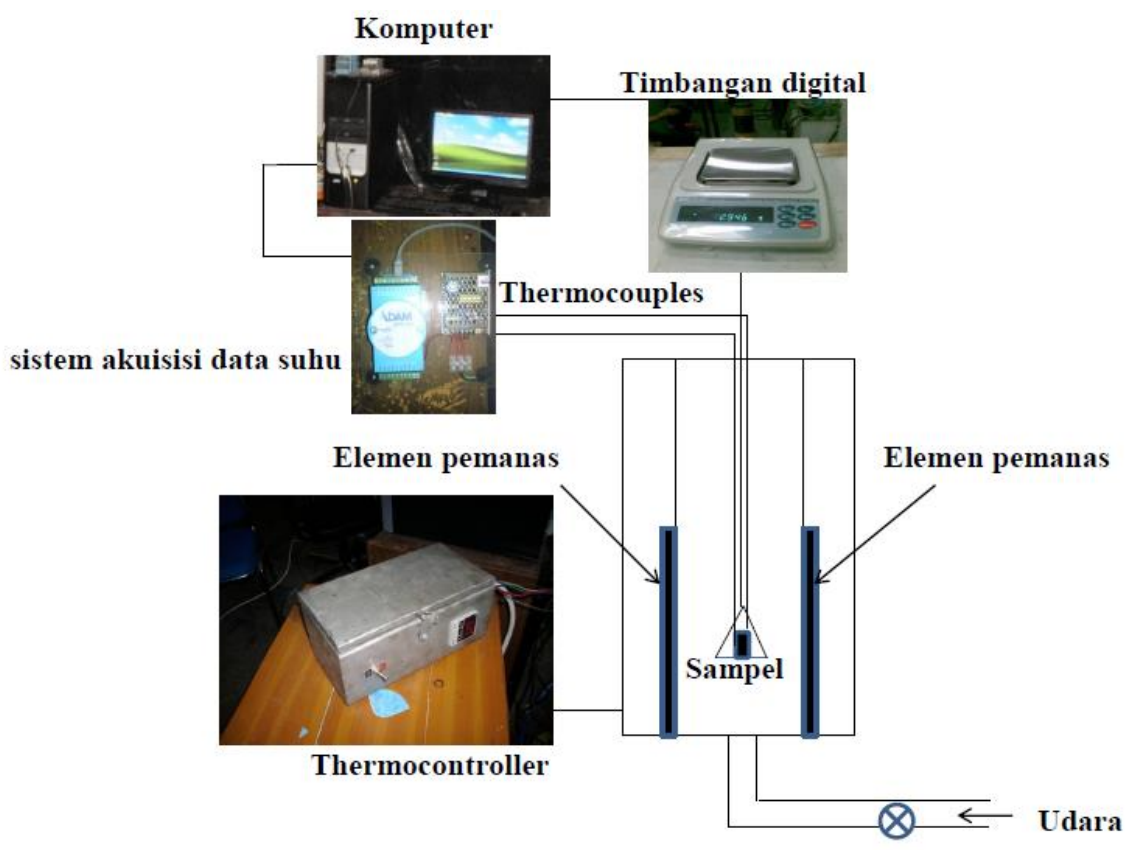

Gambar 1. Skema alat uji pembakaran yang digunakan

\subsection{Cara Penelitian}

Penelitian dimulai dengan pembuatan briket char dengan material yang telah ditentukan. Pembuatan briket dilakukan dengan jalan ditekan dalam sebuah mesin pres hingga berbentuk silindris, dengan tekanan pengepresan 250 $\mathrm{kg} / \mathrm{cm}^{2}$ dan lama holding time (penahanan tekanan) selama 1 menit. Briket arang sampah kota tersebut dibuat dengan menggunakan perekat tepung kanji dengan berat $20 \%$ dari berat total briket. Berat sampel briket char sampah kota adalah seberat 3 gram. Briket char sampah kota yang telah dibuat, kemudian dikeringkan untuk mengurangi kadar air. Selanjutnya dilakukan uji laju pembakaran. untuk melakukan uji laju pembakaran dengan cara dilakukan dalam sebuah tungku elektrik, seperti terlihat dalam Gambar 1, yang mampu dikontrol temperaturnya sampai dengan $700^{\circ} \mathrm{C}$.

Sampel briket char sampah kota dengan bentuk silinder dengan berat 3 gram diletakkan dalam sebuah wadah dan diletakkan ditengah-tengah tungku elektrik tersebut kemudian dipanaskan dengan temperatur tertentu sampai 
terbakar habis. Adapun uji pembakaran dilaksanakan dengan menggunakan dua metode, yaitu pertama metode thermogravimetry, metode ini dilakukan dengan cara menaikkan temperatur ruang bakar dari temperatur kamar secara bertahap dengan besar kenaikan konstan tiap waktu sebesar $20{ }^{0} \mathrm{C} /$ menit, sampai sampel bahan bakar terbakar habis. Sementara metode yang kedua adalah metode isothermal furnace, dimana briket char sampah akan diletakkan dalam sebuah reaktor/furnace dengan temperatur ruang tertentu sampai terbakar habis, variasi temperatur ruang bakar yang dipilih adalah $250{ }^{\circ} \mathrm{C}, 500{ }^{\circ} \mathrm{C}$ dan $600{ }^{\circ} \mathrm{C}$. Pada pengujian pembakaran secara isothermal furnace dilakukan pada kecepatan aliran udara $0,1 \mathrm{~m} / \mathrm{s}$.

\section{HASIL DAN PEMBAHASAN}

\subsection{Penentuan Energi Aktivasi Pembakaran dengan Metoda Thermogravimetry}

Pada Gambar 2 disajikan grafik karakteristik pembakaran sampel dengan menggunakan metoda thermogravimetry.

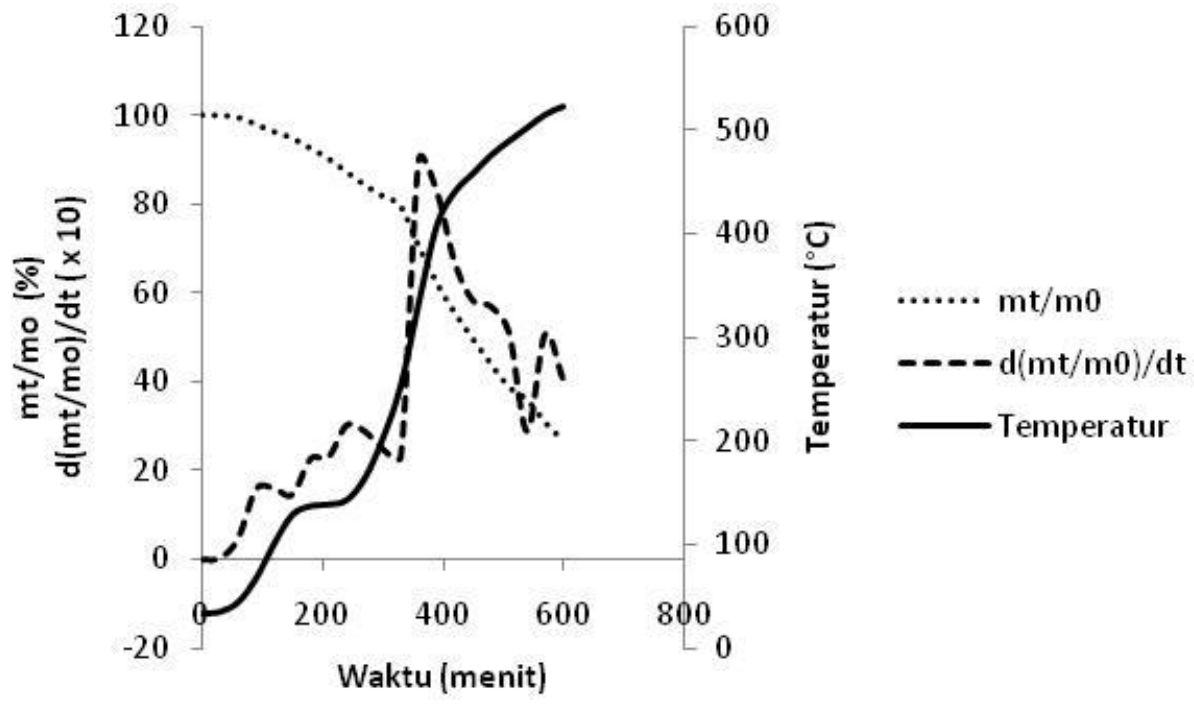

Gambar 2. Karakteristik pembakaran sampel dengan menggunakan metoda thermogravimetry

Dalam Gambar 2 tersebut, tampak bahwa sampel mulai mengalami pembakaran pada di kisaran suhu $253,4{ }^{\circ} \mathrm{C}$, sementara laju pengurangan maksimum terjadi pada temperatur 333,3 ${ }^{\circ} \mathrm{C}$. Semakin rendah suhu awal pembakaran berkaitan pada rendahnya energi awal yang diperlukan untuk memulai reaksi pembakaran, dengan kata lain briket lebih mudah dibakar, sedangkan temperatur dimana terjadi laju pengurangan massa maksimum tinggi menunjukkan bahwa briket yang dibakar akan lebih lama, sehingga hal tersebut akan membawa dampak pada awetnya pemakaian briket.

Perhitungan energi aktivasi proses pembakaran sampel dalam penelitian ini didasarkan dengan menggunakan rumus perhitungan kinetika reaksi berorde satu atau yang lazim disebut global kinetic. Penentuan besaran energi aktivasi dilakukan dengan metode grafis dengan rumusan yang digunakan berdasarkan pada persamaan Arrhenius. Pemilihan metoda global kinetic, didasarkan bahwa pada penelitian ini tidak memandang reaksi elementer yang terjadi, namun hanya memandang kecepatan char bereaksi sehingga habis terbakar. Rumusan yang digunakan dalam perhitungan global kinetic pembakaran briket char dalam penelitian adalah sebagai berikut [6], [7] dan [8],

$$
\frac{\mathrm{dx}}{\mathrm{dt}}=\mathrm{Ae}^{-\frac{\mathrm{E}}{\mathrm{RT}}}(1-\mathrm{x})
$$

dimana $\mathrm{E}$ adalah energi aktivasi, $\mathrm{R}$ adalah kostanta reaksi universal, A adalah faktor pre eksponensial atau faktor frekuensi yang merupakan satu besaran yang merepresentasikan jumlah tumbukan (collisions) molekul yang ber-reaksi dan $\mathrm{T}$ adalah suhu, sementara $\mathrm{x}$ adalah fraksi massa, yang dihitung dengan rumusan

$$
\mathrm{x}=\frac{\mathrm{m}_{0}-\mathrm{m}}{\mathrm{m}_{0}-\mathrm{m}_{\mathrm{f}}}
$$

dengan $\mathrm{m}$ adalah adalah massa sampel saat waktu ke-t, $\mathrm{m}_{0}$ adalah massa awal sampel dan $\mathrm{m}_{\mathrm{f}}$ adalah massa akhir sampel.

Laju kenaikan suhu (heating rate) didefiniskan sebagai

$$
\beta=\frac{\mathrm{dT}}{\mathrm{dt}}
$$

dengan menggabungkan persamaan (1), (2) dan (3), persamaan (1) menjadi 
Dwi Aries Himawanto, Penentuan Energi Aktivasi Pembakaran Briket Char Sampah Kota dengan Menggunakan Metoda Thermogravimetry dan Iso Thermal Furnace

$$
\frac{\mathrm{dx}}{\mathrm{dT}}=\frac{\mathrm{A}}{\beta} \mathrm{e}^{-\frac{\mathrm{E}}{\mathrm{RT}}}(1-\mathrm{x})
$$

atau

$$
\frac{d x}{(1-x)}=\frac{A}{\beta} e^{-\frac{E}{R T}} d T
$$

bila kedua ruas diintegralkan, maka persamaan (5) akan menjadi

$$
-\ln (1-\mathrm{x})=\frac{\mathrm{A}}{\beta} \int \mathrm{e}^{-\frac{\mathrm{E}}{\mathrm{RT}}} \mathrm{dT}
$$

Pada persamaan (6), suku $\int \mathrm{e}^{-\frac{\mathrm{E}}{\mathrm{RT}}} \mathrm{dT}$, merupakan integral tidak eksak namun dapat dinyatakan dalam asymptotic series sehingga persamaan (6) tersebut dapat diintegralkan menjadi

$$
\begin{gathered}
-\ln (1-x)=\frac{\mathrm{ART}^{2}}{\beta \mathrm{E}}\left[1-\frac{2 \mathrm{RT}}{\mathrm{E}}\right] \mathrm{e}^{-\frac{\mathrm{E}}{\mathrm{RT}}}, \\
-\frac{\ln (1-\mathrm{x})}{\mathrm{T}^{2}}=\frac{\mathrm{AR}}{\beta \mathrm{E}}\left[1-\frac{2 \mathrm{RT}}{\mathrm{E}}\right] \mathrm{e}^{-\frac{\mathrm{E}}{\mathrm{RT}}}, \\
\ln \left[-\frac{\ln (1-\mathrm{x})}{\mathrm{T}^{2}}\right]=\ln \left[\frac{\mathrm{AR}}{\beta \mathrm{E}}\left[1-\frac{2 \mathrm{RT}}{\mathrm{E}}\right]\right]-\frac{\mathrm{E}}{\mathrm{RT}},
\end{gathered}
$$

pada kenyataannya suku $\frac{2 \mathrm{RT}}{\mathrm{E}} \ll 1$ sehingga bisa diabaikan

$$
\ln \left[-\frac{\ln (1-x)}{\mathrm{T}^{2}}\right]=\ln \left[\frac{\mathrm{AR}}{\beta \mathrm{E}}\right]-\frac{\mathrm{E}}{\mathrm{RT}}
$$

Dengan membuat grafik hubungan antara $\ln \left[-\frac{\ln (\mathbf{1}-\mathbf{x})}{\mathbf{T}^{2}}\right]$ dan $1 / \mathrm{T}$, maka didapatkan garis lurus dimana kemiringan garis tersebut adalah -E/R, sehingga didapatkan harga E. Grafik penggambaran hubungan antara $\ln \left[-\frac{\ln (\mathbf{1}-\mathbf{x})}{\mathbf{T}^{2}}\right]$ dan $1 / \mathrm{T}$ proses pembakaran sebagai dasar perhitungan energi aktivasi pembakaran briket sampel dalam penelitian ini terlihat dalam Gambar 3.

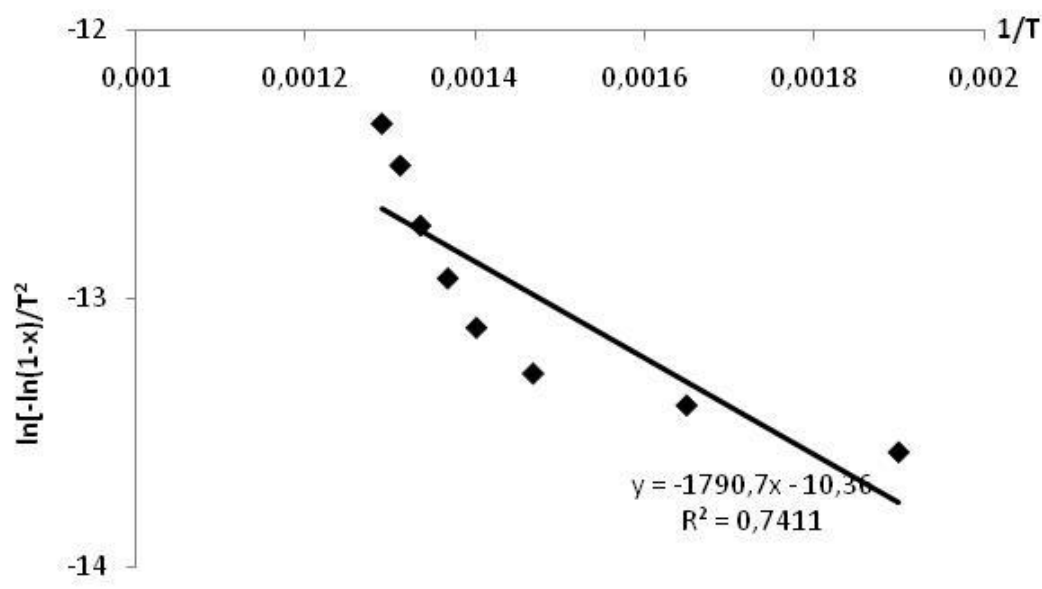

Gambar 3. Penentuan energi aktivasi pembakaran sampel dengan menggunakan metoda thermogravimetry

Dari Gambar 3, maka dapat diketahui bahwa energi aktivasi pembakaran sampel uji dengan mengunakan metoda thermogravimetry adalah sebesar $14,88 \mathrm{~kJ} / \mathrm{mol}$.

\subsection{Penentuan Energi Aktivasi Pembakaran dengan Metoda Isothermal Furnace}

Dalam Gambar 4 disajikan gambar karakteristik pengurangan massa sampel pada saat uji pembakaran dengan menggunakan metoda isothermal furnace. 


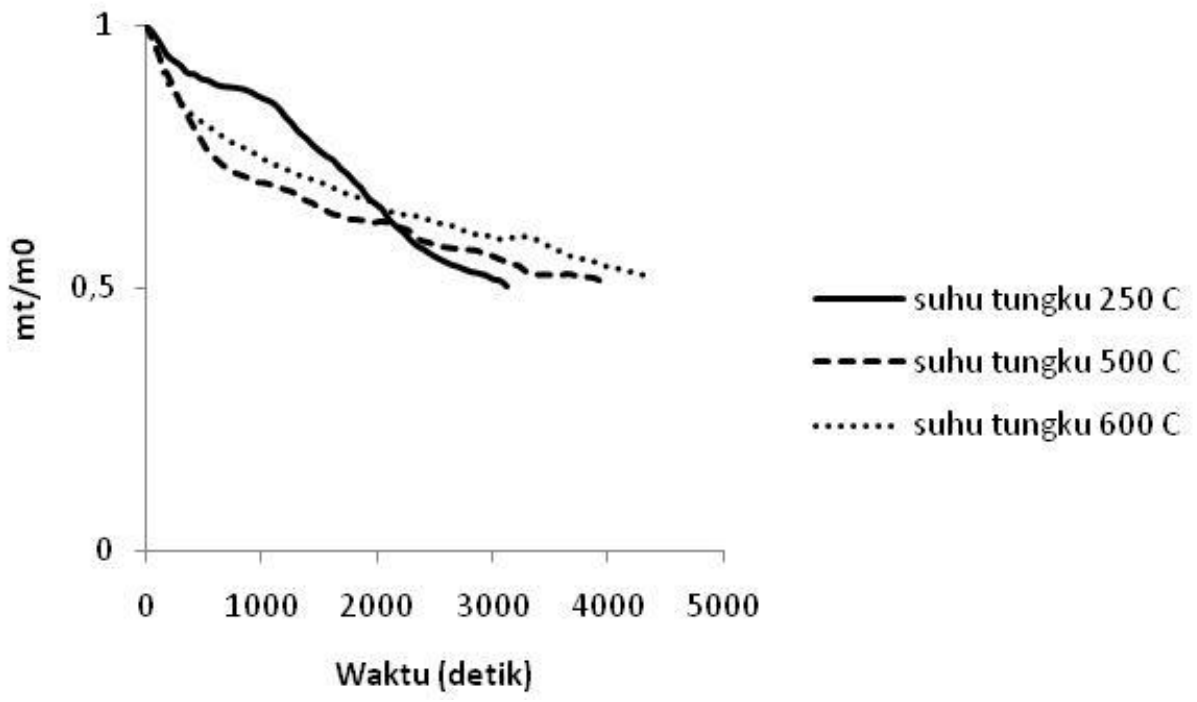

Gambar 4. Karakteristik pembakaran sampel dengan menggunakan metoda isothermal furnace

Dalam Gambar 4 tersebut, tampak bahwa untuk suhu $250{ }^{\circ} \mathrm{C}$, kurva pengurangan massa sampel uji lebih landai jika dibandingkan dengan dengan dua kurva pada suhu yang lain, hal ini diduga pada suhu $250{ }^{\circ} \mathrm{C}$, sampel memerlukan waktu yang lebih lama untuk menaikkan suhu sampel hingga mencapai suhu dimana sampel dapat mulai terbakar.

Perhitungan energi aktivasi dengan menggunakan metoda isothermal furnace, sebenarnya sama dengan metoda thermogravimetry, yaitu dengan menggunakan rumusan Arrhenius, namun untuk metoda isothermal furnace, dilakukan secara bertahap berdasarkan suhu reaktor yang dipilih. Formula yang digunakan untuk reaksi dengan orde reaksi 1 adalah sebagai berikut [9],

$$
-\frac{\mathrm{dm}}{\mathrm{dt}}=\mathrm{km} \quad
$$

dimana m adalah massa sampel saat waktu ke-t dan k adalah konstanta kecepatan reaksi. Persamaan (11) diatas dapat dituliskan

$$
-\frac{d\left(m-m_{f}\right)}{d t}=k\left(m-m_{f}\right)
$$

dimana $\mathrm{m}_{\mathrm{f}}$ adalah massa sampel saat akhir reaksi, dengan menyususn persamaan (12) dan mengintegralkan , maka persamaan (12) akan menjadi

$$
-\ln \left(\frac{m-m_{f}}{m_{0}-m_{f}}\right)=k t
$$

Untuk setiap suhu reaktor yang dipilih, hubungan antara $-\ln \left(\frac{m-m_{f}}{m_{0}-m_{f}}\right)$ dengan $\mathrm{t}$ (waktu) merupakan garis lurus dengan slope garis merepresentasikan harga $\mathrm{k}$ (konstanta kecepatan reaksi), sementara persamaan Arrhenius menyatakan

$$
k=k_{0} e^{\left(\frac{-E}{R T}\right)}
$$

bila kedua ruas dalam persamaan (14) di-ln-kan, maka persamaan (14) dapat dinyatakan sebagai

$$
\ln k=\ln k_{0}-\frac{E}{R T}
$$

Grafik hubungan antara ln $\mathrm{k}$ dan 1/T merupakan garis lurus dengan slope yang besarnya sama dengan E/R. Dengan menggambarka hubungan antara $\ln \mathrm{k}$ dan 1/T untuk ketiga suhu reaktor yang dipilih, maka dapat ditentukan harga energi aktivasi pembakaran untuk sampel uji.

Dalam Gambar 5, Gambar 6 dan Gambar 7 ditampilkan gambar hubungan antara $-\mathbf{l n}\left(\frac{\boldsymbol{m}_{\boldsymbol{n}} \boldsymbol{m}_{\boldsymbol{f}}}{\boldsymbol{m}_{\mathbf{0}}-\boldsymbol{m}_{\boldsymbol{f}}}\right)$ dan waktu (t) untuk berturut-turut suhu reaktor $250{ }^{\circ} \mathrm{C}, 500{ }^{\circ} \mathrm{C}$ dan $600{ }^{\circ} \mathrm{C}$, dimana masing-masing dihasilkan nilai konstanta 
kecepatan reaksi $0,0006 \operatorname{det}^{-1}, 0,0009 \operatorname{det}^{-1}$ dan $0,0012 \operatorname{det}^{-1}$. Dari hasil tersebut, kemudian digambarkan grafik hubungan antara $\ln \mathrm{k}$ dan 1/T untuk semua suhu reaktor yang digunakan, seperti terlihat dalam Gambar 8 .

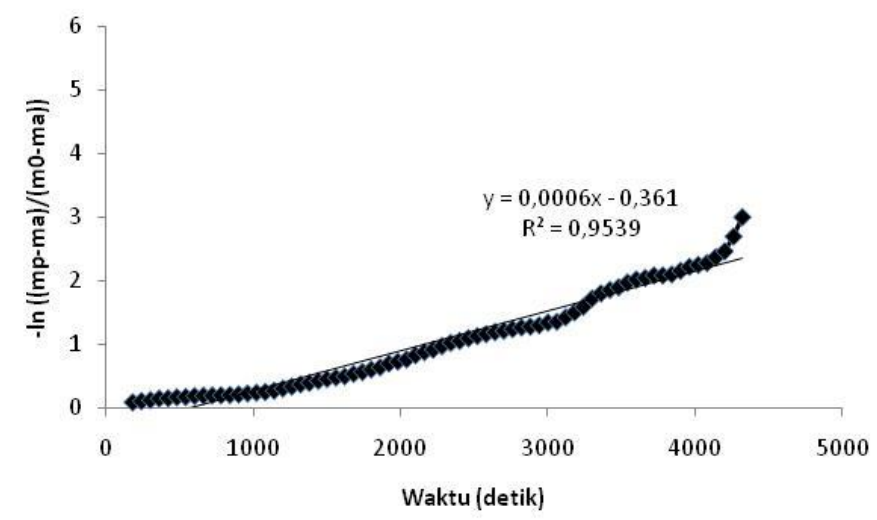

Gambar 5. Grafik hubungan $-\ln \left(\frac{m-m_{f}}{m_{0}-m_{f}}\right)$ dengan waktu untuk suhu furnace $250{ }^{\circ} \mathrm{C}$

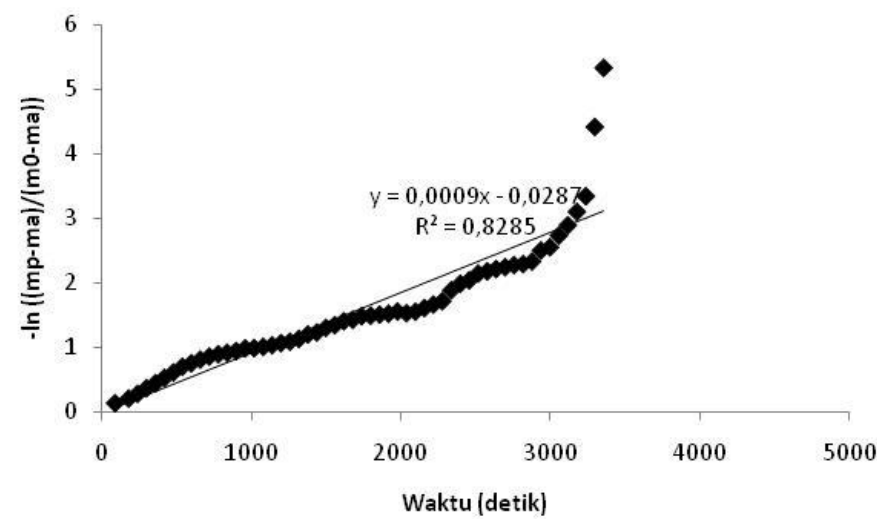

Gambar 6. Grafik hubungan $-\ln \left(\frac{m-m_{f}}{m_{0}-m_{f}}\right)$ dengan waktu untuk suhu furnace $500{ }^{\circ} \mathrm{C}$

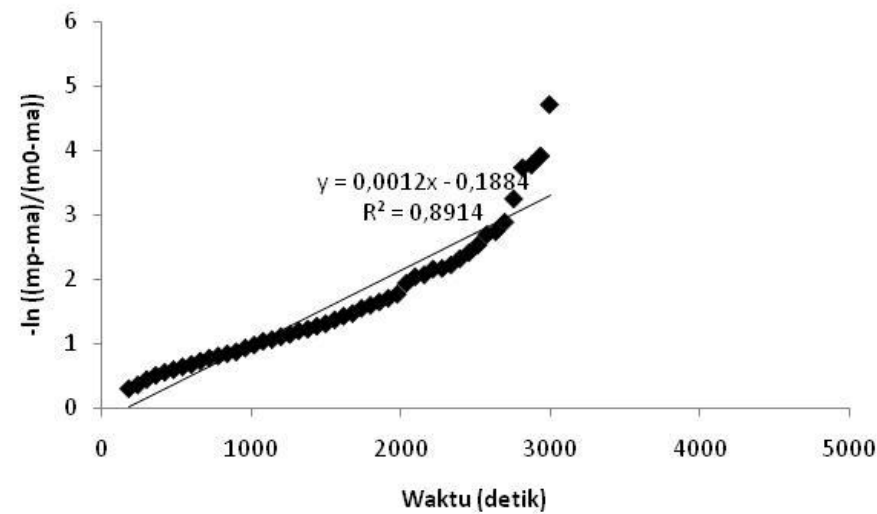

Gambar 7. Grafik hubungan $-\ln \left(\frac{m-m_{f}}{m_{0}-m_{f}}\right)$ dengan waktu untuk suhu furnace $600{ }^{\circ} \mathrm{C}$ 


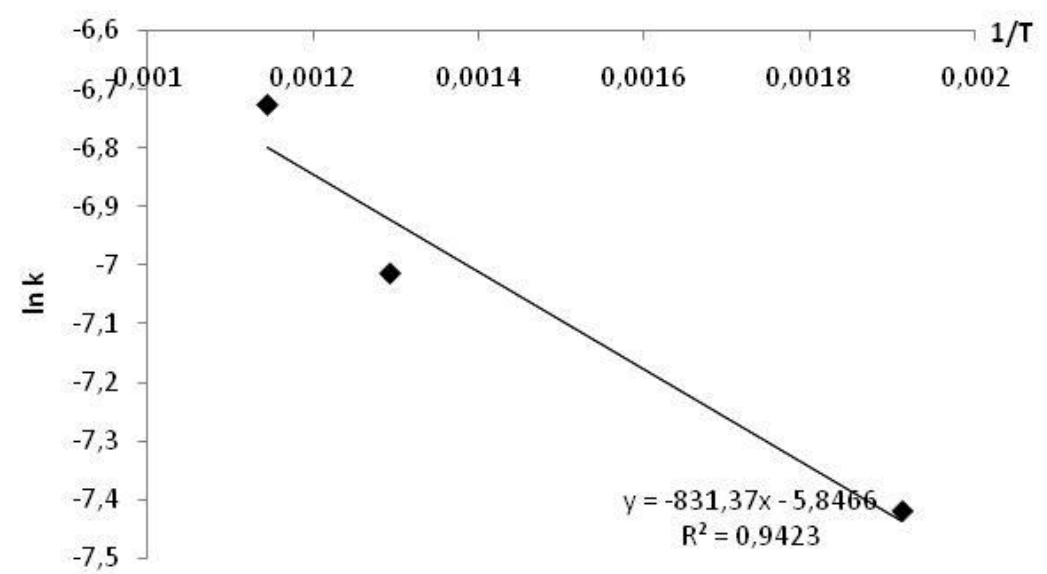

Gambar 8. Grafik hubungan ln $\mathrm{k}$ dan 1/T untuk penentuan energi aktivasi pada pengujian dengan metoda isothermal

furnace

Dari Gambar 8 dapat dihitung bahwa energi aktivasi pembakaran sampel uji adalah sebesar 6,91 kJ/mol.

\subsection{Pembahasan}

Dari hasil perhitungan energi aktivasi briket char sampel dengan metoda thermogravimetry memberikan hasil $14,88 \mathrm{~kJ} / \mathrm{mol}$, sementara dengan metoda isothermal furnace memberikan hasil 6,91 kJ/mo. Perbedaan hasil perhitungan energi aktivasi yang didapatkan diduga terkait dengan pemilihan suhu awal reaksi pembakaran pada metoda thermogravimetry dan pemilihan suhu pada metoda isothermal furnace. Pemilihan suhu awal terjadinya pembakaran dengan metoda thermogravimetry cukup sulit dilakukan, karena tidak adanya batas yang jelas antara zona $d r y i n g$, devolatilisasi, pembakaran fixed carbon dan pembakaran abu pada pembakaran char, hal ini berimplikasi pada sulitnya menentukan suhu awal pembakaran arang yang menjadi dasar perhitungan energi aktivasi pembakaran. Semeentara itu pemilihan besar dan banyaknya suhu isothermal dalam metoda isothermal furnace sangat menentukan besarnya energi aktivasi proses pembakaran.

Sebagai pembanding hasil penelitian, energi aktivasi pembakaran briket char $R D F$ yang dibuat dari kertas bekas dan koran bekas sebesar $62,3 \mathrm{~kJ} / \mathrm{mol}$ sedangkan untuk pellet kertas $56,4 \mathrm{~kJ} / \mathrm{mol}$ [9], faktor yang diduga menjadi penyebab besarnya energi aktivasi yang didapatkan dalam penelitian ini adalah porositas dari briket, dimana dalam penelitian tersebut densitas dari briket yang diteliti dijaga pada kisaran $1.200 \mathrm{~kg} / \mathrm{m}^{3}$ hingga $1.360 \mathrm{~kg} / \mathrm{m}^{3}$, sementara densitas briket char yang diteliti dalam penelitian ini adalah $80,29 \mathrm{~kg} / \mathrm{m}^{3}$. Perbedaan densitas ini akan membawa pengaruh kepada morfologi dan porositas dari briket.

Dugaan tersebut diatas diperkuat oleh satu hasil penelitian yang menyatakan bahwa penentuan energi aktivasi pembakaran char sulit dilakukan karena beberapa hal diantaranya bentuk morfologi char dan range laju pembakaran yang luas [10] dan ketebalan lapisan abu pada permukaan briket akan menghambat difusi oksigen dan gas hasil pembakaran ke dalam dan keluar briket [5]. Hasil penelitian lain mengenai pengembangan teori pembakaran one film model, mengungkapkan bahwa specific reaction rate (Rs) dapat ditruliskan sebagai berikut

$$
\frac{1}{R s}=\left(\frac{1}{k_{1} p_{s}}\right)+\left(\frac{1}{k_{2}}\right) \text {, }
$$

dimana Rs merupakan specific reaction rate, $\mathrm{p}_{\mathrm{s}}$ konsentrasi oksigen pada pemukaan bahan bakar padat, $\mathrm{k}_{1}$ konstanta kecepatan proses adsorpsi dan $\mathrm{k}_{2}$ merupakan konstanta kecepatan desorpsi, dan didapatkan kecepatan desorpsi tergantung pada porositas bahan [11]. Hal tersebut diperkuat oleh adanya analisa mengenai masalah hubungan antara parameter kinetik dari pembakaran arang (char) dengan sifat sifat batu bara., dengan menyatakan bahwa untuk menentukan specific burning rate dari char digunakan rumusan

$$
g_{c}=k_{0, c} \cdot f(s) \cdot \rho_{s} \cdot Y_{0, s} \exp \left(-E /\left(R T_{p}\right)\right)
$$

dimana $\mathrm{g}_{\mathrm{c}}$ adalah specific burning rate dari pembakaran char $\left(\mathrm{kg} / \mathrm{m}^{2} / \mathrm{s}\right), \mathrm{f}(\mathrm{s})$ merupakan efek specific surface area dari char, $\mathrm{Y}_{0, \mathrm{~s}}$ merupakan konsentrasi oksigen pada permukaan char sementara $\rho_{\mathrm{s}}$ densitas char [12]. 


\section{KESIMPULAN}

Dari hasil penelitian, dapat disimpulkan bahwa metoda isothermal furnace dapat digunakan untuk melakukan perhitungan energi aktivasi pembakaran seperti halnya metoda thermogravimetry. Beberapa hal yang mempengaruhi tingkat kevalidan hasil perhitungan energi aktivasi pembakaran dengan menggunakan metoda isothermal furnace adalah pemilihan suhu reaktor yang dipilih, banyaknya kondisi isothermal yang digunakan dan sifat-sifat fisis dari briket, terutama sifat morfologis dan porositas briket.

\section{UCAPAN TERIMA KASIH}

Artikel ini merupakan sebagian hasil penelitian dari penelitian Hibah Bersaing tahun anggaran 2010 yang didanai oleh DP2M Ditjen Dikti Kementerian Pendidikan Nasional Penulis mengucapkan terima kasih kepada Prof.Dr.Ir. Indarto, DEA., Prof.Dr.Ing.Ir. Harwin Saptoadi, MSE. dan Dr.Eng. Tri Agung Rohmat, B.Eng., M.Eng., selaku sesama tim peneliti kegiatan Hibah Bersaing 2010 ini yang telah telah memberikan ijin kepada penulis untuk mempublikasikan hasil penelitian. Terima kasih juga penulis sampaikan kepada saudara Zainudin dan saudara Novi Caroko, yang telah membantu penelitian ini.

\section{DAFTAR PUSTAKA}

[1] Borman,G.L., Ragland, K.W., 1998, Combustion Engineering, McGraw-Hill Book Co., Singapore, International Editions 1998

[2] Rhen, C., Ohman, M., Gref, R., Wasterlund, I., 2007, Effect of Raw Material Composition in Woody Biomass Pellets on Combustion Characteristics, Biomass and Bioenergy 31 (2007) pp. 66-72

[3] Cheng, Z., Chen, H., Zhang, Y., Hack, P., Pan, W.P., 2007, An Application of Thermal Analysis to Household Waste, Journal of ASTM International Vol, 4 N0. 1., Paper ID : JAI100523

[4] Grammelis,P., Basinas, P., Malliopoulou, A., Sakellaropoulos, G., 2009, Pyrolisis Kinetics and Combustion Characteristics of Waste Recovered Fuels, Fuel 88 (2009), pp. 195-205

[5] Hart,S. Ward, J., Biffin, M., 2001, Development of a Method To Asses The Reactivity of Multi-Component Solid Fuel Briquette, IFRF Combustion Journal Article Number 200106, June 2001, pp. 1-18

[6] Himawanto, D. A., Indarto, Saptoadi, H., \& Rohmat ,T. A., 2011, Karakteristik dan Pendekatan Kinetika Global pada Pirolisis Lambat Sampah Kota Terseleksi, Reaktor, ISSN 0852-0798, Vol.13 No.3 Juni 2011, Hal. 140-147

[7] Himawanto, D.A., Sidhi, P.R, Indarto, Saptoadi, H., Rohmat, T.R., 2011, Analisa Thermogravimatery Pembakaran Briket Char Bambu, Jurnal Teknik Mesin, vol. 11 no. 1, hal. 77-85

[8] Himawanto, D. A., Indarto, Saptoadi, H., Rohmat, T. A.,2012, Thermogravimetric Analysis and Global Kinetics of Segregated MSW Pyrolysis, Modern Applied Science, 6 (1), 120-130

[9] Siritheerasas, P., Sawasdee, P. Inthakanok, S. 2008, Combustion of a Single-particle Refuse-derived Fuel (RDF), Thammasat Int. J. Sc. Tech., Vol.13 Special Edition, November 2008, pp. 80-85

[10] Wornat, M. J., Hurt, R. H., Davis, K. A., \& Yang, N. Y. C. (1996). Single Particle Combustion of Two Biomass Chars, Symposium (International) on Combustion, 26(2), 3075-3083

[11] Essenhigh,R.H.,Froberg,R.,Howard,J.B.,1965, Combustion Behavior of Small Particles, Industrial and Engineering Chemistry Vol. 57 No. 9, 32-43

[12] Fu,W.B., Zhang,B.L., Zheng,S.M., 1997, A Relationship Between the Kinetic Parameters of Char Combustion and the Coal's Properties, Combustion and Flame 109, pp. 587-598 